\title{
Vascular endothelial growth factor induces growth of uterine cervix and immune cell recruitment in mice
}

\section{Siobhan M Donnelly, Bao Tran Nguyen, Scott Rhyne, Jordan Estes, Subrina Jesmin ${ }^{1}$ and Chishimba Nathan Mowa}

Department of Biology, Appalachian State University, Rankin Science North Building N219, 572 River Street, Boone, North Carolina 28608, USA

${ }^{1}$ Department of Internal Medicine, Tsukuba University, Tsukuba, Japan
Correspondence should be addressed to C N Mowa

Email

mowacn@appstate.edu

\begin{abstract}
Knowledge of uterine cervical epithelial biology and factors that influence its events may be critical in understanding the process of cervical remodeling (CR). Here, we examine the impact of exogenous vascular endothelial growth factor (VEGF) on uterine cervical epithelial growth in mice (nonpregnant and pregnant) treated with VEGF agents (recombinant and inhibitor) using a variety of morphological and molecular techniques. Exogenous VEGF altered various uterine cervical epithelial cellular events, including marked induction of growth, edema, increase in inter-epithelial paracellular space, and recruitment of immune cells to the outer surface of epithelial cells (cervical lumen). We conclude that VEGF induces multiple alterations in the uterine cervical epithelial tissues that may play a role in local immune surveillance and uterine cervical growth during CR.
\end{abstract}

- VEGF

- uterine cervical growth and immune cell recruitment

\section{Introduction}

During pregnancy, the uterine cervix undergoes a marked growth, particularly in the last half of pregnancy (Downing \& Sherwood 1985, Hwang \& Sherwood 1988), where uterine cervical weight gain increases as much as threefold in rats (Zarrow \& Yochim 1961, Hwang et al. 1989). Notably, and of relevance to this study, proliferation of uterine cervical epithelial cells, in addition to stromal cells, accounts for almost all the uterine cervical growth that occurs during pregnancy (Buchanan et al. 1998). A detailed understanding of uterine cervical epithelial biology has become essential because it is now believed that they play important and broad range of roles during uterine cervical remodeling (CR), which include i) maintaining fluid balance via synthesis of hydrophilic hyaluronan, glycosaminoglycan, and aquaporins; ii) proliferation and differentiation; iii) regulation of paracellular transport of solutes via tight junctions; iv) providing a protective barrier against invading microorganisms, and mediating inflammatory and adaptive immune responses; and v) acting as an 'endocrine' gland by synthesizing prostaglandins, chemokines, and cytokines (e.g. interleukin-8) and steroid hormones (Barclay et al. 1993, Pfundt et al. 1996, Mahendroo et al. 1999, Minjarez et al. 2000, Word et al. 2007). It is likely, as some studies suggest that uterine cervical epithelial cells may play the central role in CR.

To date, the key factors believed to modulate uterine cervical growth are relaxin and estrogen (Kroc et al. 1959, Cullen \& Harkness 1960, Downing \& Sherwood 1985, Hwang \& Sherwood 1988). Further, the uterine cervical growth-stimulating effects of relaxin are believed to be mediated by the estrogen/ER $\alpha$ genomic pathway, as mice

Published by Bioscientifica Ltd 
lacking ER $\alpha$ administered with relaxin do not display uterine cervical growth compared to the wild-type group, with an intact ER $\alpha$ (Yao et al. 2010). Because of the redundant nature of most CR processes, uterine cervical growth is also likely to be regulated by multiple factors, either in a synergistic or complementary manner. It is interesting to note that, like relaxin, vascular endothelial growth factor (Vegf) expression is, in part, induced by estrogen both in the uterus and in the uterine cervix, and has a temporal, and to some extent, spatial relationship with plasma estrogen levels (Mowa \& Papka 2004, Mowa et al. 2004, 2008, Lee \& Sherwood 2005). Further and intriguingly, relaxin stimulates robust expressions of VEGF in the uterus and is known to exhibit VEGF-like biological effects, including angiogenesis and vascular permeability, in humans and rodents (see review Dschietzig \& Stangl (2003)). We do not know at this point the functional relationship between relaxin and VEGF in the uterine cervix.

We have previously characterized the presence and profile of VEGF, the key architect of vascular events, and its key receptors in the uterine cervix of rodents (mice and rats) and delineated VEGF-related genes using DNA microarray analysis (Mowa \& Papka 2004, Mowa et al. 2004, 2008, Newell et al. 2008, Nguyen et al. 2012). The effects of VEGF are mediated by two tyrosinekinase receptors, namely VEGFR-1 (Flt1) and VEGFR-2 $(K d r / F l k 1)$, which have different signaling properties and are largely expressed by endothelial cells (Ferrara 2009). Other cellular targets of VEGF, which express VEGF receptors, include osteoblasts, mononuclear phagocytes, hematopoietic cells, and some malignant cells (Chen et al. 2004, Ferrara 2009). We recently noted using scanning electron microscopy (SEM) that when ovariectomized mice were treated with exogenous recombinant VEGF administered intravaginally, it (VEGF) induced pronounced folding of the uterine cervical epithelial lining (Mowa et al. 2008). The increase in uterine cervical epithelial folding was interpreted as induction of uterine cervical epithelial proliferation, implying that VEGF may also be a possible regulator of uterine cervical growth.

In this study, we apply a more definitive technique, i.e. bromodeoxyuridine (BrdU), to determine whether VEGF induces uterine cervical epithelial proliferation. We also examine other structural and molecular changes induced by VEGF in uterine cervical epithelial cells and the whole uterine cervical tissue in general, notably the effect of VEGF on the recruitment of immune cells to the uterine cervical epithelia and lumen.

\section{Materials and methods}

\section{Animals}

Pregnant and nonpregnant (ovariectomized) C57BL6/ 129SvEv mice (Mus musculus) sourced from Charles Rivers were used in these studies $(n=3)$ either treated or under different physiological conditions, as described in detail below. Before tissue harvest, animals were administered a lethal injection of sodium pentobarbital (Sleepaway, Fort Dodge Laboratories, Inc., Burlingame, CA, USA) and perfused intracardially immediately thereafter with $0.9 \%$ normal saline. Uterine cervical tissues were carefully harvested under a stereomicroscope, to avoid tissue contamination from vaginal or uterine tissues, and the tissues were then processed and analyzed appropriately. Animals were housed under constant room temperature (RT), with a $12 \mathrm{~h}$ light:12 h darkness cycle and had free access to water and feed. All experiments were performed in accordance with the Guide for the Care and Use of Laboratory Animals of the local institution (Appalachian State University) and the NIH guidelines (NIH publication number 86-23), and efforts were made to minimize both animal suffering and numbers of animals used. Following treatments, tissues were analyzed using various techniques, including morphological techniques (basic immunohistochemistry (BrdU, SEM) and gene expression (real-time PCR)), in order to elucidate the effects of VEGF on various uterine cervical parameters and events, namely uterine cervical epithelial structure and proliferation.

\section{Treatments}

Nonpregnant ovariectomized mice Before treatments or tissue harvest, sexually mature mice $\sim 6$-weeks old weighing between 30 and $40 \mathrm{~g}$ were ovariectomized (ovariectomy $=$ removal of ovaries). Prior to ovariectomy, animals were anaesthetized with ketamine and xylazine (43-129 mg ketamine and 8.6-26 mg xylazine/g) and then rested for 7 days post-surgery to allow excretion of residual ovarian sex steroid hormones. Significant reduction in uterine size during tissue harvest indicated complete excretion of residual ovarian hormones. Animals with normal uterine size 7 days after ovariectomy were eliminated from the study. Appropriate treatments were administered by injecting either vehicle only (negative control: 0.1 M PBS mixed with saturated (25\%) pluronic gel and kept in liquid form under ice) or VEGF agonist (mouse recombinant VEGF 164 protein (Calbiochem, La

Published by Bioscientifica Ltd. 
Jolla, CA, USA)) to nonpregnant ovariectomized mice ( $n=3$ /treatment group), following dosage, frequency, and route optimization, as described below and previously (Nguyen et al. 2012). Some mice were also treated with VEGF inhibitor (PTK 787/ZK22584; generously provided by Novartis Pharma AG):

Dose-dependent optimization Animals were divided into two groups and treated with $50 \mu$ of either: i) increasing doses of mouse recombinant VEGF 164 protein (50 ng/mouse, $200 \mathrm{ng} / \mathrm{mouse}$, or $400 \mathrm{ng} / \mathrm{mouse}$ ) or ii) vehicle only (0.1 M PBS). Both groups were initially injected either i.p. and or intravaginally (via intraluminal administration) (data not shown), once in the morning $(1000 \mathrm{~h})$ and once in the evening $(1600 \mathrm{~h})$ respectively daily for 4 days. Two hundred nanograms (200 ng) of exogenous VEGF were found to be the optimal dosage (Nguyen et al. 2012). After treatment, tissues were harvested and split into ecto-cervix (uterine cervix portion proximal to vagina) and endo-cervix (uterine cervix portion proximal to uterus) by cutting the tissue transversely midway. The tissues were then immediately fixed in $2.5 \%$ glutaraldehyde (dissolved in $0.1 \mathrm{M}$ PBS) for SEM analysis (morphology). In later experiments of this study, we eliminated chronic treatments $(>24 \mathrm{~h}$ treatments) for nonpregnant ovariectomized animals, following results of a detailed optimization study of exogenous VEGF treatment by another project in our laboratory (Nguyen et al. 2012).

Time-dependent optimization Animals were treated with a single injection (i.p.) of recombinant VEGF (200 ng/mouse, i.p.) at time $0 \mathrm{~h}$ and tissues were harvested in a time-dependent manner, i.e. $1 \mathrm{~h} 45 \mathrm{~min}, 2 \mathrm{~h} 45 \mathrm{~min}$, and $4 \mathrm{~h} 45 \mathrm{~min}$ post-VEGF treatment, as described earlier, and fixed in $10 \%$ formalin for $24 \mathrm{~h}$ before processing them further for basic histological and immunohistochemical studies.

Cell proliferation and height Animals were treated with a single injection (i.p.) of recombinant VEGF (200 ng/mouse, i.p.) in a time-dependent manner, as described under section Dose-dependent optimization earlier. In addition, a day before and during VEGF treatment, both groups were also treated with $50 \mu$ li.p.) of BrdU, a uridine derivative and a structural analog of thymidine, according to the manufacturer's instruction (Invitrogen). BrdU is incorporated into DNA during the synthesis phase of the cell division as a substitute for thymidine, thus can serve as a marker for proliferation. Intestines from either group (VEGF- or vehicle only-treated groups) were used as positive control tissues. Animals were killed on the second day and tissues were then harvested, fixed in 10\% formalin, and analyzed using immunohistochemistry and basic histology (H\&E stain) (Inverted Zeiss Light Microscope).

\section{Determining optimal duration of VEGF treat-} ment This study was designed to determine the optimal duration of VEGF treatment, i.e. single vs repeat treatments. Animals were divided into two treatment groups $(n=3)$ as follows: i) group 1 was given a single injection of recombinant VEGF (200 ng dissolved in $25 \mu \mathrm{l}$ of saturated pluronic gel and $0.1 \mathrm{M}$ PBS, $25 \mu \mathrm{l}$ per injection, intravaginal (IV)) administered at time $=0 \mathrm{~h}$, whereas ii) group 2 was given two consecutive injections of recombinant VEGF (same dosage, solvent/media and route as in group 1) administered at time $=0$ and $4 \mathrm{~h}$ respectively. Both groups of animals were killed at $4 \mathrm{~h}$ after-their last injection, tissues were then harvested and frozen at $-80^{\circ} \mathrm{C}$, and examined using quantitative real-time PCR.

\section{Pregnant mice}

Pregnant mice (days 11 and 17) 10- to 12-week old, weighing between 60 and $80 \mathrm{~g}$, were used, as described below:

\section{Baseline gene expression study (untreated)}

Untreated timed pregnant animals (days 11 and 17 of pregnancy, $n=3$ ) were used in order to determine the baseline gene expression pattern of VEGF and its receptors (KDR and Flt1) in the uterine cervix. Animals were killed at noon and tissues were then harvested and frozen at $-80{ }^{\circ} \mathrm{C}$, processed, and examined using quantitative real-time PCR.

\section{Gene expression studies of animals treated with} VEGF agents (exogenous VEGF and VEGF inhibitor)

Pregnant animals (days 11 and 17) were treated with either vehicle only or VEGF agents (exogenous VEGF and inhibitor) via intraluminal IV, twice a day, morning $(1000 \mathrm{~h})$ and afternoon $(1600 \mathrm{~h})$, as described here: i) group 1 was given two consecutive injections of recombinant VEGF (200 ng dissolved in $25 \mu$ of saturated pluronic gel and $0.1 \mathrm{M}$ PBS, $25 \mu \mathrm{l} /$ per injection, IV); ii) group 2 was given two consecutive injections of VEGF inhibitor ( $5 \mathrm{mg}$ VEGF inhibitor/kg body weight, $50 \mu \mathrm{l} /$ per injection, i.p.; and iii) group 3 was given two consecutive

Published by Bioscientifica Ltd. 
injections of vehicle $(25 \mu$ l of saturated pluronic gel and $0.1 \mathrm{M}$ PBS, $25 \mu \mathrm{l} /$ per injection).

\section{Techniques}

Determination of VEGF's effects on uterine cervical epithelial morphology using SEM Experiments were undertaken to visualize the effects of VEGF on the morphology of uterine cervical epithelia of ovariectomized mice. After fixing tissues overnight in 2.5\% glutaraldehyde, the tissues were processed for SEM analysis by first washing the tissues in the buffer, then dehydrated in a graded series of ethanol, and critically dried using a Polaron critical point drying apparatus (Polaron Instruments, Inc., Doylestown, PA, USA). Whole tissue samples were then mounted on aluminum stubs sputter coated with gold and imaged using a Quanta 200 SEM (FEI Company, Hilsboro, OR, USA) at $20 \mathrm{kV}$.

Determination of VEGF's effects on uterine cervical epithelial proliferation and height using BrdU and basic histology This experiment was undertaken to test our earlier speculation that VEGF causes cervical epithelial cell growth based on increased cervical epithelial folds, as revealed by SEM data (Mowa et al. 2008), using one of the gold standard tests for cell proliferation, i.e. BrdU. After treatment, described earlier (see Treatment, Cell proliferation), animals were killed and tissues were processed and sectioned using cryostat, and sections were stained with anti-BrdU and processed further using immunohistochemistry, according to the manufacturer's instructions (Invitrogen). Following staining, sections were counterstained with hematoxylin, dehydrated in a series of ethanol, and dipped in xylene before mounting. In another of our earlier studies that revealed that VEGF induced increased uterine cervical epithelial folds at a much lower dosage of VEGF (Mowa et al. 2008), we used tissues from that study to measure epithelial height of uterine cervix using mounted sections viewed and analyzed under a microscope (inverted Zeiss DIC light microscope). The average height of uterine cervical epithelial cells (30 cells) was obtained using the software MicroSuite Five (2009) for each treatment group and plotted as a graph, to determine the effects of treatments on epithelial height.

\section{Determination of Vegf mRNA expression and its receptors (Flt1 and KDR) in mice uterine cervix}

Gene expression analysis was performed using real-time PCR to determine the effects of VEGF agents (recombinant
VEGF164 protein and VEGF inhibitor) on the mRNA expression of Vegf and its receptors, KDR and Flt1, in the uterine cervix of pregnant mice. Gene expression analysis was performed in three steps, as described below:

i) Tissue processing, mRNA isolation, and quantification: following treatments, animals were killed and transcardially perfused with normal saline $(0.9 \%$ sodium chloride). The cervices were harvested immediately, snap-frozen, and either processed or stored at $-80^{\circ} \mathrm{C}$ until processing. Total RNA was isolated from individual uterine cervices using the RNeasy Mini Kit (Qiagen) and then the quality and quantity of each sample were estimated using Nanodrop Spectrophotometer (Nanodrop, Wilmington, DE, USA). Aliquots of total RNA were diluted in RNase-free deionized (DI) water and either stored at $-80{ }^{\circ} \mathrm{C}$ or processed for reverse transcriptase PCR, as described below.

ii) Reverse transcriptase PCR (RT-PCR): total RNA from the uterine cervical tissues was reverse transcribed and amplified in an Eppendorf Master Cycler (Hamburg, Germany) using reagents from Applied Biosystems. For generation of cDNA, $1.0 \mu \mathrm{g}$ of previously isolated total RNA was placed in a total volume of $9.5 \mu$ per sample with RNase-free water, as determined by Nanodrop Spectrophotometer, described earlier. The RNA was incubated for $5 \mathrm{~min}$ at $65^{\circ} \mathrm{C}$ and cooled to RT for $10 \mathrm{~min}$, then $9.5 \mu \mathrm{l}$ of reverse transcriptase master mix was added to each tube, which comprised reverse transcriptase buffer $(2 \mu$ per tube of RNA; Applied Biosystems); $\mathrm{MgCl}_{2}$ ( $2 \mu$ l per tube of RNA; Applied Biosystems), dNTP ( $2 \mu$ l per tube of RNA; Applied Biosystems), RNase inhibitor $(0.5 \mu \mathrm{l}$ per tube of RNA; Applied Biosystems), RNAse-free water ( $2 \mu \mathrm{l}$ per tube of RNA; Applied Biosystems), and random hexamers ( $1 \mu \mathrm{l}$ per tube of RNA; Applied Biosystems). Lastly, $1.0 \mu \mathrm{l}$ of MuLV reverse transcriptase (Applied Biosystems) was added to each tube. One tube received no reverse transcriptase enzyme to serve as a nontemplate control for DNA contamination. The thermocycler was programmed to run at $25^{\circ} \mathrm{C}$ for $10 \mathrm{~min}, 42^{\circ} \mathrm{C}$ for $2 \mathrm{~h}, 95^{\circ} \mathrm{C}$ for $5 \mathrm{~min}$, and $4{ }^{\circ} \mathrm{C}$. The generated total cDNA was then used to evaluate mRNA levels of the genes of interest, as described below.

iii) Real-time PCR: relative expressions of the genes of interest ( $V e g f, K d r$, and Flt1) were evaluated using real-time PCR. Only fold changes $>2$ were accepted as significant. TaqMan Gene Expression Assays (Applied Biosystems), which are pre-designed and pre-optimized gene-specific probe sets, were used and DNA amplification was performed using the Applied Biosystems real-time PCR machine (ABI 7300 HT) with the GeneAmp 7300 HT sequence detection system software (Perkin-Elmer Corp.)

Published by Bioscientifica Ltd. 
The real-time PCRs were set up in wells of 96-well plates in a volume of $25 \mu \mathrm{l}$ per well. The reaction components included $1000 \mathrm{ng}(5.0 \mu \mathrm{l})$ of synthesized cDNA, $12.5 \mu \mathrm{l} 2 \mathrm{X}$ Taqman Universal PCR Master Mix, $1.25 \mu \mathrm{l}$ 20X Assays-onDemand Gene Mix (e.g. VEGF), and $6.25 \mu l$ real-time PCR-grade RNAse-free water. The program was set as follows: an initial step of $50^{\circ} \mathrm{C}$ for $2 \mathrm{~min}$ and $95^{\circ} \mathrm{C}$ for $10 \mathrm{~min}$ and then 40 cycles of $95^{\circ} \mathrm{C}$ for $15 \mathrm{~s}$ and $60^{\circ} \mathrm{C}$ for $60 \mathrm{~s}$. The relative amount was calculated from the threshold cycles with the instrument's software (SDS 2.0), according to the manufacturer's instructions. Relative expression levels of the target genes were normalized to the geometric mean of the endogenous control gene, Gus $\beta$.

\section{Results}

VEGF alters the ultrastructure of uterine cervical epithelial cells and induces transepithelial recruitment of WBC

SEM analysis of ecto- and endo-uterine cervical tissues from ovariectomized animals treated with exogenous VEGF revealed pronounced alterations in the ultrastructure of uterine cervical epithelial cell compared with the control groups (Figs 1, 2 and 3). Specifically, in ecto- cervices, VEGF induced folds, edema-like appearance, and less pronounced inter-epithelial cellular borders), compared with the control group (Fig. 1). In endo-cervices, the most striking features of VEGF on uterine cervical epithelial cells were the dose-dependent recruitment and transepithelial migrations of white blood cells (WBC) into the uterine cervical lumen, which was not observed in ecto-cervix. Furthermore, as with ecto-cervix, the inter-epithelial borders in endo-cervix were also less prominent due perhaps to edema (Fig. 2), and increase in inter-epithelial paracellular space was obvious even at a much lower dosage, a feature that was attenuated by VEGF inhibitor (Fig. 3). At the dose of $400 \mathrm{ng} /$ mouse of recombinant VEGF, there was a much greater infiltration and migration of WBC into the uterine cervical lumen of endo-cervices. However, at this dosage, the uterine cervical epithelial layer began to peel-off in both the ecto- and endo-cervices (data not shown).

\section{VEGF induces proliferation of uterine cervical epithelial cells}

Treatment of ovariectomized mice with VEGF induced pronounced proliferation of uterine cervical epithelial cells in a time-dependent manner, and the peak growth occurred at $4 \mathrm{~h} 45 \mathrm{~min}$ post-VEGF treatment, with the
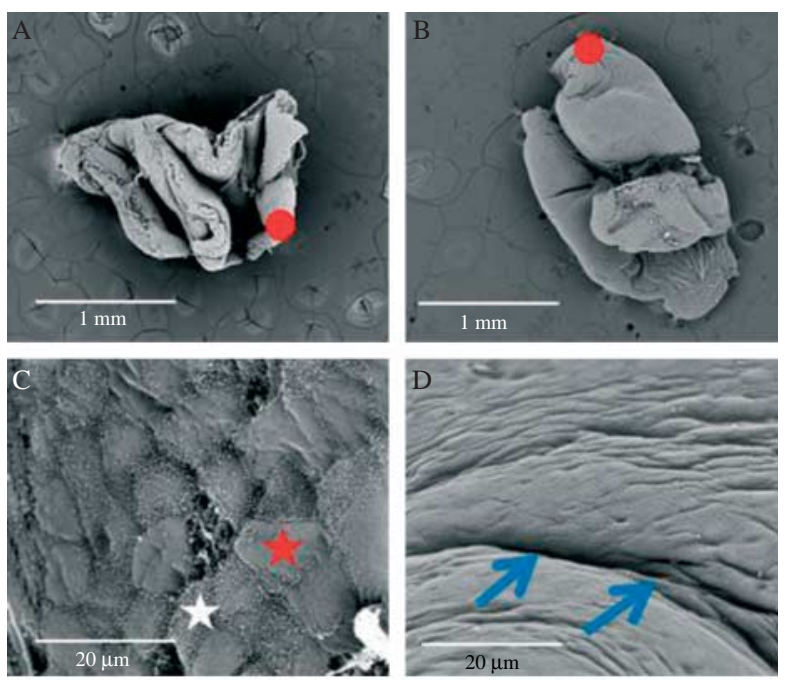

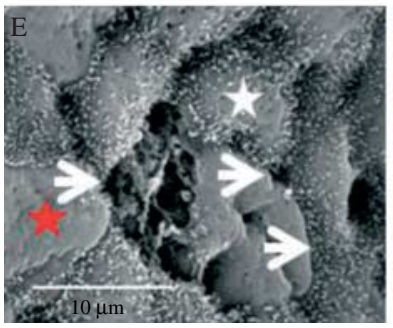

Control

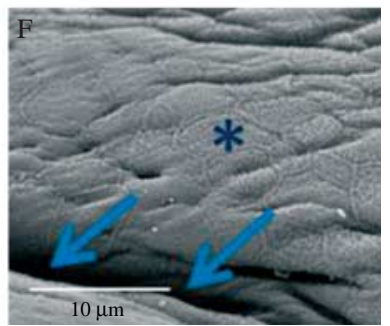

200 ng VEGF

\section{Figure 1}

VEGF alters the ultrastructure of uterine cervical epithelial cell, as revealed by SEM images. Ovariectomized mice treated with VEGF recombinant protein 164 (B, D and F) ( $200 \mathrm{ng} /$ mouse, single treatment of either i.p. or intravaginal) induces folds (blue arrows) and a general swelling in uterine cervical epithelial sheets compared with ovariectomized control group treated with vehicle only, i.e. PBS (A, C and E), where cell types (red and white stars) and borders (short white arrows) are more distinct than in VEGF-treated mice (*). Red circle in $A$ and $B$ are sites on the ecto-side of the uterine cervix from which images $\mathrm{C}, \mathrm{D}, \mathrm{E}$ and $\mathrm{F}$ were taken $(n=3)$. Magnification: $A$ and $B=\times 100 ; C$ and $D=\times 5000 ; E$ and $F=\times 10000$.

least at $1 \mathrm{~h} 45 \mathrm{~min}$ (Fig. 4) and $6 \mathrm{~h}$ (data not shown) postVEGF treatment respectively. Further, VEGF treatment at a much lower dosage of $20 \mathrm{ng} /$ mouse $(\sim \times 5$ lower) almost doubled epithelial height compared with control group, i.e. $12 \mu \mathrm{m}$ (VEGF) vs. $7.5 \mu \mathrm{m}$ (control) (Fig. 5).

\section{VEGF alters gene expression of VEGF and its receptors in uterine cervices of pregnant mice}

Uterine cervix mRNA levels of VEGF and its receptors were found to be unchanged between gestational days 11 through 16 but increased sharply by day $17(P<0.05)$ (Fig. 6). Treatment of pregnant animals with VEGF at days 11 but not 17 of pregnancy tended to upregulate VEGF and its two receptors, KDR and Flt1, whereas blockage of

Published by Bioscientifica Ltd. 

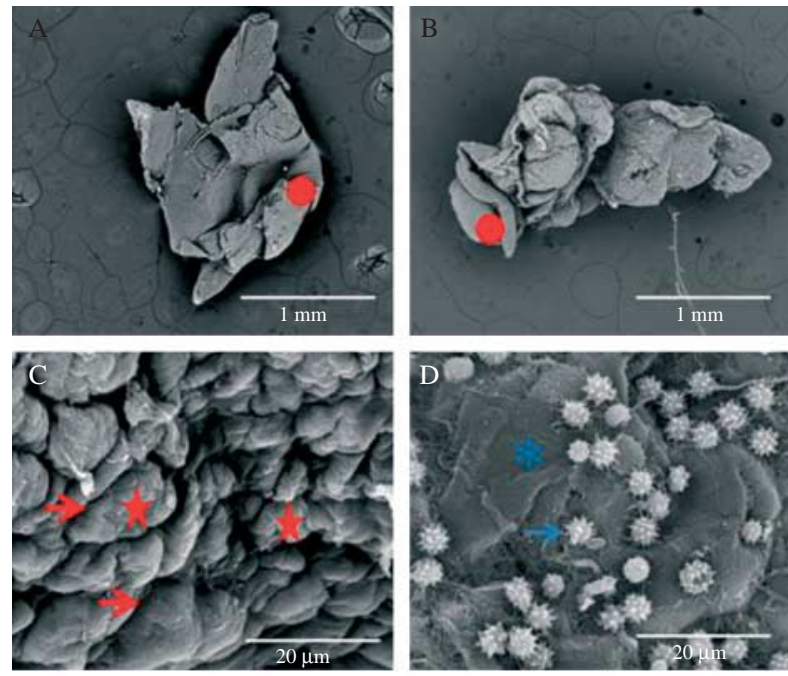

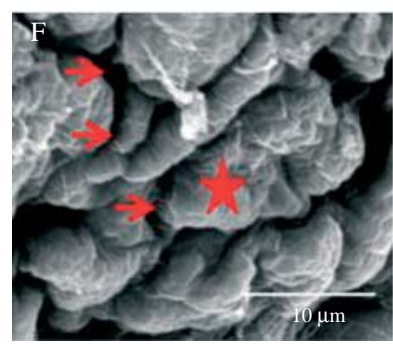

Control

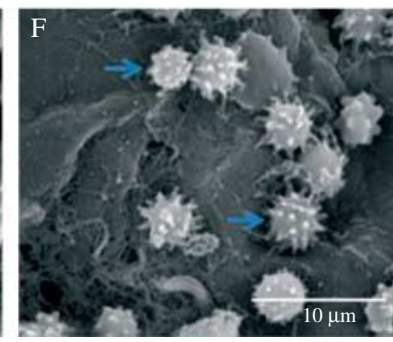

200 ng VEGF
Figure 2

VEGF induces recruitment of WBC on the outer surface of uterine cervical epithelial cell or lumen, as revealed by SEM images: ovariectomized mice treated with VEGF recombinant protein 164 (B, D and F) (200 ng/mouse, single treatment of either i.p. or intravaginal) causes WBC (blue arrows) recruitment from uterine cervical tissue into the uterine cervical lumen and a change in cellular shape compared with ovariectomized control group treated with vehicle only, i.e. PBS (A, C and E). Cells in control group (red stars) have distinct borders (red arrows) compared with VEGF-treated mice $\left.{ }^{*}\right)$. Red circle in $A$ and $B$ are sites on the endo-side of the uterine cervix from which images $C, D, E$ and $F$ were taken $(n=3)$. Magnification: $A$ and $B=\times 100 ; C$ and $D=\times 5000 ; E$ and $F=\times 10000$.

endogenous VEGF at day 11 but not 17 of pregnancy using VEGF inhibitor downregulated expression of VEGF and its receptors, KDR and Flt1 (Fig. 7).

\section{Discussion}

Uterine cervical epithelial cells are now believed to play a central role in uterine CR by regulating multiple functions, cited earlier in the introduction (Barclay et al. 1993, Pfundt et al. 1996, Mahendroo et al. 1999, Minjarez et al. 2000, Word et al. 2007). We have previously shown that exogenous VEGF administered to ovariectomized mice induces folding of the uterine cervical epithelia layer using SEM and interpreted these data to mean that VEGF induces proliferation of uterine cervical epithelial cells (Mowa et al. 2008). This study builds on these earlier observations and was primarily aimed at investigating the effects of VEGF on uterine cervical epithelial cell proliferation using a more definitive technique, namely BrdU. The key findings of this study are that VEGF promotes i) proliferation of uterine cervical epithelial cells in a temporal- and dose-dependent manner; ii) WBC transepithelial recruitment from the tissue into the uterine cervical lumen; and iii) folding and edema in uterine cervical epithelial cells. Collectively, these findings suggest that VEGF may influence uterine CR, in part, by influencing a variety of uterine cervical epithelial cell events, such as uterine cervical epithelial cell proliferation, transepithelial cell recruitment, and local immune surveillance. The observed effects of VEGF on epithelial events may have physiological significance that may impact CR (Fig. 8).

In the second half of pregnancy, the uterine cervix of rats rapidly proliferates, i.e. by as much as threefold, an effect that is largely attributed to the actions of relaxin and estrogen (Downing \& Sherwood 1985, Hwang \& Sherwood 1988). The effects of relaxin on uterine cervical growth (stromal and epithelial cells), which accounts for 40-50\% of uterine cervical growth, is believed to be mediated by estrogen, as mice lacking $\mathrm{ER} \alpha$ and administered with relaxin have low uterine cervical and vaginal wet weight compared with wild type (Cooke, LoTurco and Sherwood, unpublished). Also the temporal and, to some extent, spatial expression patterns of these two molecules and their respective receptors coincides (Kroc et al. 1959, Cullen \& Harkness 1960). Estrogen is also known to promote uterine cervical growth independent of relaxin (Kroc et al. 1959). Because relaxin receptors are only localized in the uterine cervical stromal, but not epithelial cells, it is believed that relaxin influences epithelial growth via a paracrine mechanism, which has also been described in the uterus and other tissues (Yao et al. 2010). However, the exact mechanisms of relaxin's proliferative effects are not fully understood, as exogenous estrogen downregulates relaxin receptors in ovariectomized rat (Kumar and Sherwood, unpublished observations).

Here, we show a novel regulatory factor that promotes uterine cervical epithelial growth, i.e. VEGF, using nonpregnant ovariectomized mice, as revealed by BrdU. This study builds on SEM data from our previous study that showed increased cervical epithelial folds following administration of exogenous VEGF and was interpreted as an indication of increased epithelial growth (Mowa et al. 2008). These (present) data are also consistent with our

Published by Bioscientifica Ltd. 

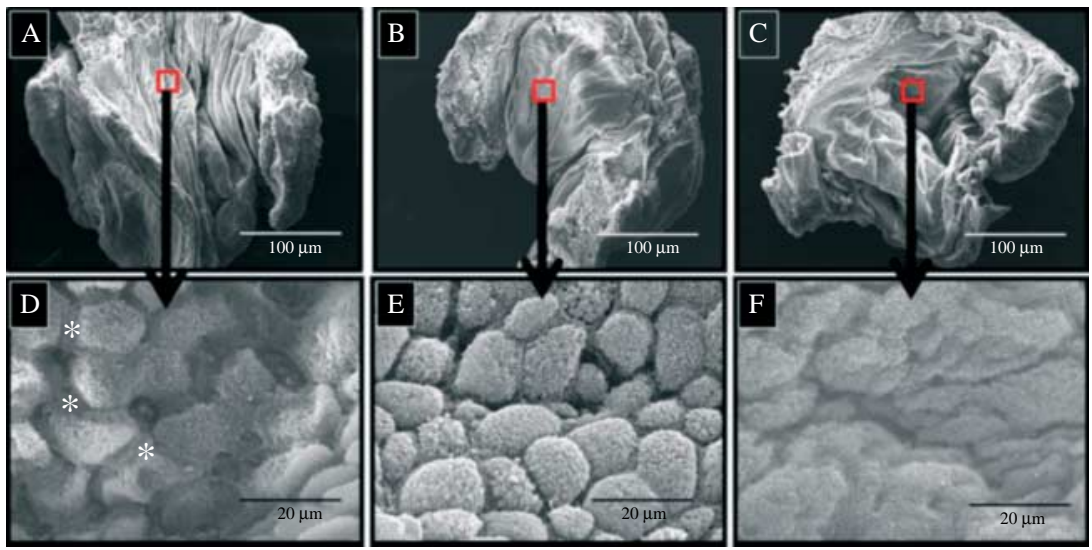

Figure 3

Effects of VEGF (low dose, $40 \mathrm{ng} /$ mouse) on uterine cervical epithelial folds and inter-epithelial gap space: (A and D) VEGF recombinant protein induces epithelial folds of uterine cervical tissue and inter-epithelial spaces ${ }^{*}$ ) respectively in ovariectomized mice compared with control (B), treated only with PBS. Figures $\mathrm{C}$ and $\mathrm{F}$ show that blocking the action of VEGF via

earlier genome-wide gene expression data that revealed sharp decreases in expression of genes associated with cell proliferation $(-8.11$-fold), cell motility $(-7.66)$, and cell adhesion molecule activity (-1.96) (Mowa et al. 2008). At this point, the precise mechanism of VEGF's proliferative effects on uterine cervical epithelial growth and its relationship with the other two regulatory factors known to promote growth of this cell type are unclear. It is, however, intriguing to note that there are some striking similarities and overlap between VEGF and the other two regulatory factors (relaxin and estrogen) in some of their administration of its inhibitor reverses the effects of VEGF and changes the normal appearance of the cells (low magnification, $\times 149$ ) compared with ovariectomized control group (E) administered with PBS only (high magnification, $\times 9000)(n=3)$.

physiological effects and mechanisms (Bani \& Bigazzi 1984, St-Louis \& Massicotte 1985, Tischer et al. 1991, Bani-Sacchi et al. 1995, Unemori et al. 1999, Seibold et al. 2002, Dschietzig \& Stangl 2003).

We here show another interesting and novel phenomenon of VEGF in the uterine cervix, i.e. induction of transepithelial migration of immune cells into uterine cervical lumen. The exact mechanism/s mediating this phenomenon is also not yet clear. However, it is equally intriguing that this novel phenomenon also strikingly resembles a well-established action of VEGF in another cell

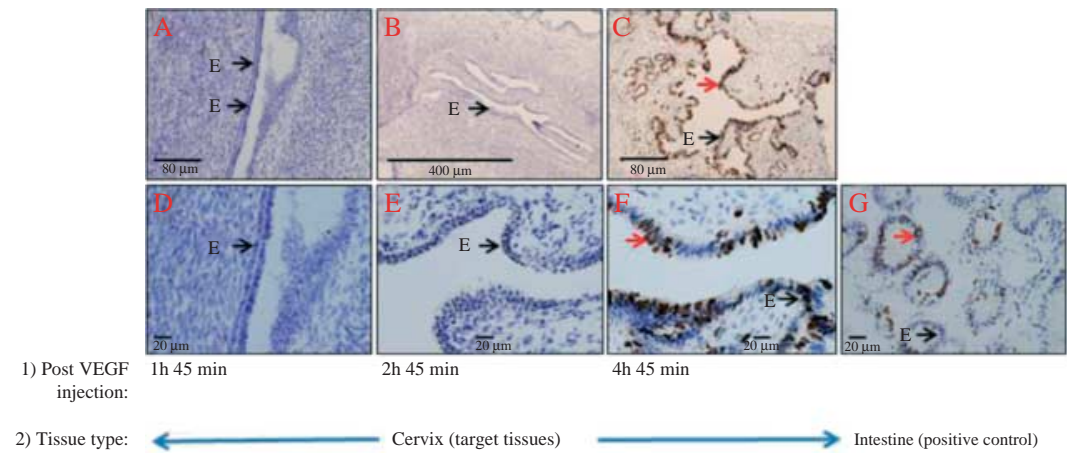

\section{Figure 4}

Effect of VEGF on uterine cervical epithelial cell proliferation: VEGF recombinant protein 164 ( $200 \mathrm{ng} /$ mouse, single treatment of either i.p. or intravaginal) induces proliferation of uterine cervical epithelial cells in ovariectomized mice, shown here using BrdU immunostaining, a marker for proliferation (red arrows point to brown staining). The maximum proliferative effects of VEGF were observed at about $5 \mathrm{~h}$ ( $\mathrm{C}$ and $\mathrm{F}$ ) and by the sixth (image not shown) post-VEGF treatment, BrdU immunostaining significantly diminished. Small intestines, which have a robust proliferation, were used as positive control tissue (G) $(n=3)$. (A, B, D and E) Black arrows point to epithelial cells, both nondividing and those undergoing proliferation. http://joe.endocrinology-journals.org DOI: 10.1530/JOE-12-0469
(C) 2013 Society for Endocrinology Printed in Great Britain
Published by Bioscientifica Ltd 


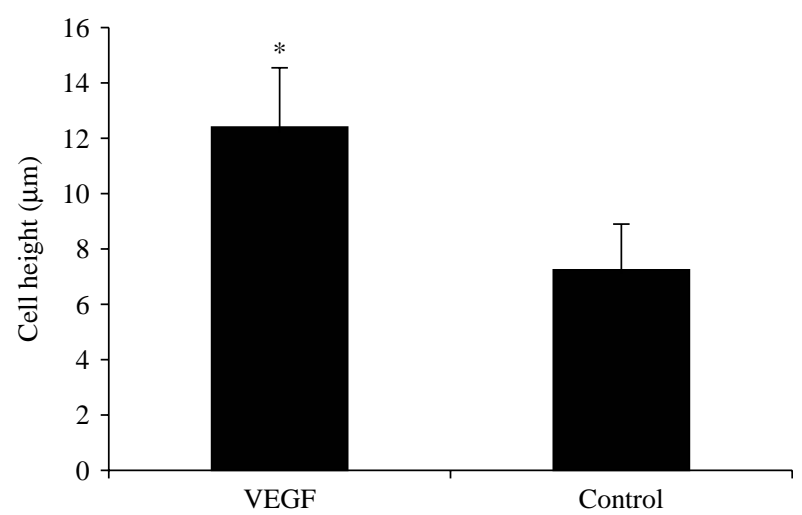

Figure 5

Effects of VEGF treatment on uterine cervical epithelial height in ovariectomized mice. Animals were either treated with recombinant VEGF ( $40 \mathrm{ng} /$ mouse daily for 2 days) or with vehicle only ( $0.1 \mathrm{M}$ PBS). Histological sections of uterine cervical epithelial tissues of these animals were then stained with H\&E and the heights of the cells were measured at $\times 60$ and plotted as a graph, shown here. The average height of the cells in animals treated with VEGF were greater than control $(n=20, * P<0.05)$.

type that is structurally similar to uterine cervical epithelia, namely vascular endothelial cells (Ferrara \& Davis-Smyth 1997). In these cells (endothelial), VEGF induces immune extravasation from blood vessels into the tissue matrix by promoting vascular permeability or increasing inter-endothelial paracellular spaces by a factor of 50000 -fold more than histamine (Van Bruggen et al. 1999). This vascular leakage, working together with established chemoattractant gradients, leads to migration of immune cells from blood vessels to the sites of injury. Our understanding of mechanisms underlying transepithelial migration of immune cells across classical or traditional epithelial cells is only a decade old and is largely derived from observations of pathogen interaction with intestinal epithelial cells (reviewed by Berkes et al. (2003)). Data from these studies have shown that invasion of epithelial cells by bacteria induces an inflammatory response through expression and secretion of a characteristic pattern of cytokines by epithelial cells (McCormick et al. 1998, Caamano \& Hunter 2002). These inflammatory responses are mediated by a variety of signaling pathways, including NFKB, PKC, and MAPK (Bird et al. 1997, Monick et al. 1999, Savkovic et al. 2002). The mobilized cytokines will then recruit a variety of effector cells, including neutrophils, lymphocytes, eosinophils, and monocytes, to the basolateral border of the invaded epithelial cells. Neutrophils will then migrate to the apical end of the epithelia and lumen, close or proximal to the invading bacteria, via the inter-epithelial cellular matrix. This second wave of migration is made possible by another set of cytokine gradients, notably IL8, secreted on the basolateral border of epithelial cells (Madara et al. 1993). The uterine cervical epithelium is composed of squamous cells on the ecto- or external portion of the uterine cervix and cuboidal cells on the internal side or endo-cervix. CR is likely to be more pronounced on the endo-cervix as it is more exposed during effacement. The significance of the differences in reaction to VEGF treatment observed between ecto- and endo-cervix in immune cell recruitment,
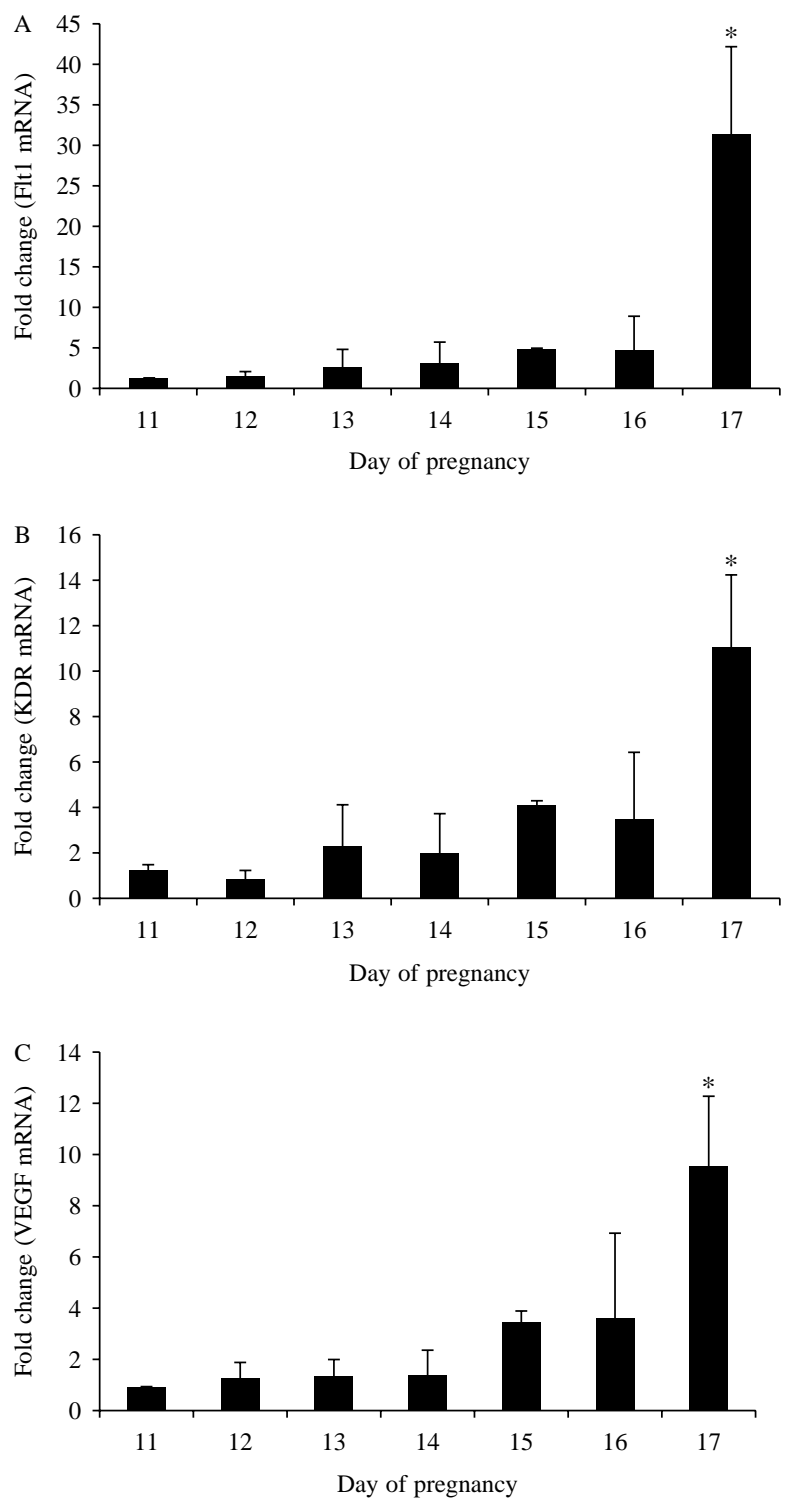

Figure 6

mRNA expression pattern of VEGF receptors, FIt1 (A) and KDR (B), and VEGF (C) in uterine cervix of pregnant mice (days 11-17), as revealed by real-time PCR. mRNA levels of all the three genes increased over the course of pregnancy. $n=3 ; * P<0.05$ for days 11 vs 17 .

Published by Bioscientifica Ltd 

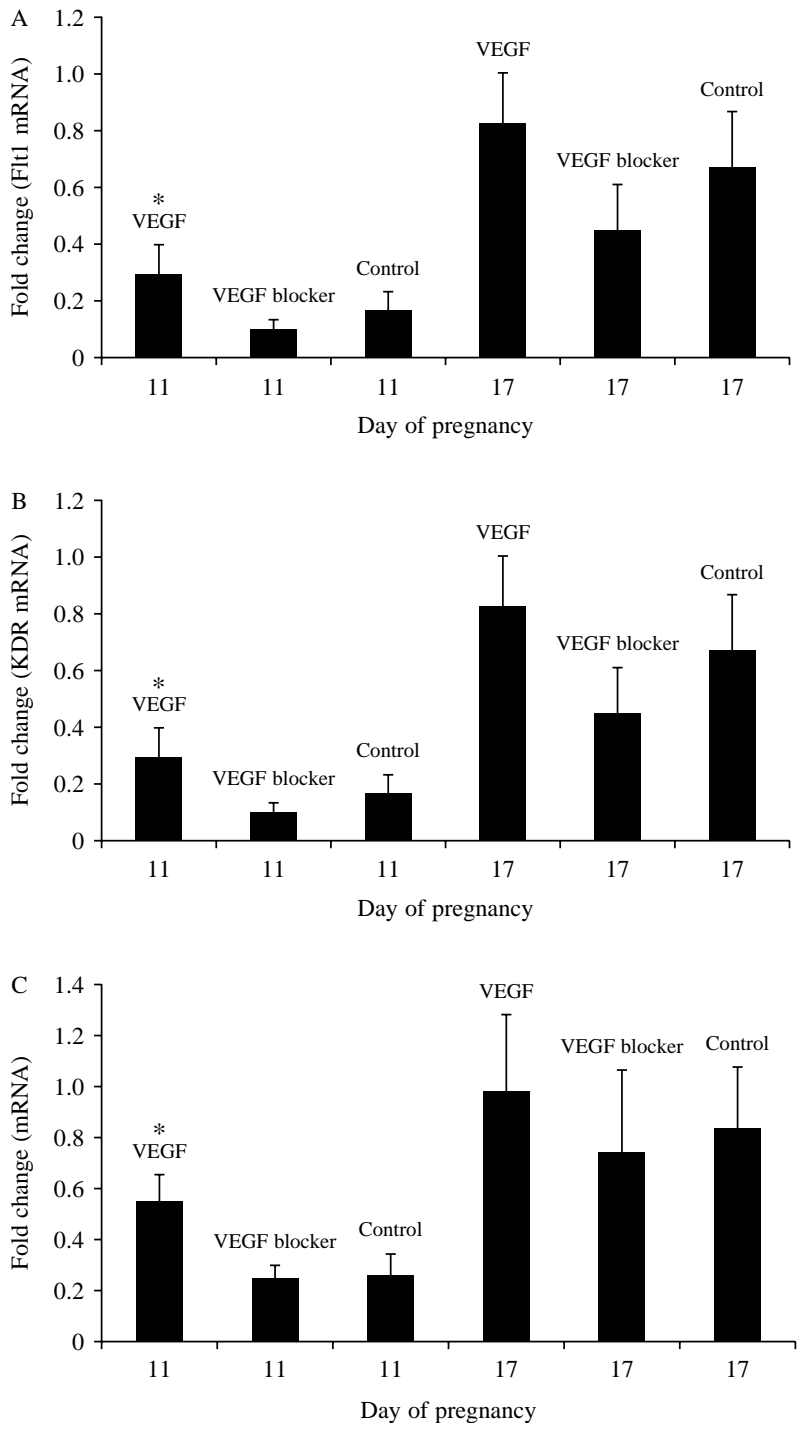

Figure 7

The effects of VEGF agents (agonist and inhibitor) on mRNA expression of VEGF receptors, FIt1 (A) and KDR (B), and on VEGF (C) in uterine cervix of pregnant mice (days 11 and 17), as revealed by real-time PCR. Generally, exogenous VEGF tended to upregulate mRNA levels of all the three genes on day 11 of pregnancy, in contrast to VEGF inhibitor, compared with the control group. $n=3 ; P<0.05$ for days marked with asterisk $\left(^{*}\right)$. However, no difference was noted in late pregnancy (day 17 ).

reported in this study, is for now unclear. We do know that there may be some differences in the barrier function of the two epithelial types. For instance, endo-cervical columnar cells appear to have tighter junctions than the superficial layers of the ecto-cervix (Blaskewicz et al. 2011). Further studies are required to tease out these differences.

We are currently investigating the exact mechanisms of VEGF in transcervical epithelial recruitment and migration of immune cells and its significance in local surveillance, and whether IL8, mediates these effects.
We recently demonstrated that exogenous VEGF administered vaginally (intraluminally) induces an inflammatory response by upregulating mRNA expression of classical pro-inflammatory factors, including TNF $\alpha$, IL6, and COX II, implying that VEGF likely plays a role in the inflammatory response of uterine cervical epithelial cells during pathogenic invasions (Nguyen et al. 2012). These observations are also consistent with our earlier DNA microarray studies that observed a 4.70 -fold decrease in genes associated with immune response and decrease in expression of an array of chemokine, interleukins, and LPS binding protein, when VEGF actions were blocked in the cervix of pregnant rats by VEGF inhibitor (Mowa et al. 2008). As for the potential role of VEGF in local surveillance, it is interesting to note that nitric oxide, the key mediator of VEGF action, has been shown to have multiple regulatory functions in intestinal epithelia, including barrier function, antimicrobial activity (De Groote \& Fang 1995, Alican \& Kubes 1996, Fang 1997), and promotion of chloride secretion (Rolfe \& Milla 1999).

VEGF was first described as a potent vascular permeability factor (Senger et al. 1986). As stated earlier, compared with other endogenous potent vascular permeability factors, such as histamine, VEGF is 50000 times stronger (Van Bruggen et al. 1999) and its role in tissue edema induction is well established, including in tissue types such as uterine, brain, and nasal tissues (Van Bruggen et al. 1999). For instance, antagonism of VEGF action in brain or stroke injury-induced edema significantly reduces swelling and hyper-permeability of brain microvasculature (Roberts \& Palade 1995, Van Bruggen et al. 1999, Dafni et al. 2002). In nasal polyps, expression of VEGF and KDR is localized in plasma cells and appears to be involved in signal transduction (Ito et al. 1995). Other conditions that may induce expression of VEGF in the brain, which in turn induces cerebrovascular permeability, include hypoxia and ischemic brain injuries (Van Bruggen et al. 1999). The exact role of edema in CR, particularly in epithelial cells, is not completely understood. One possible role is that it may provide turgor pressure, as is the case in plants and erection, i.e. the fluid pressure provides mechanical support to the otherwise softening tissues, allowing the uterine cervix to maintain its barrier properties, while at the same time remodeling and preparing itself for the final process of fetal passage or birth. Thus, VEGF likely plays two seemingly opposing roles, namely enhancing $\mathrm{CR}$, while maintaining the uterine cervical barrier properties via edema formation.

Factors and mechanisms that underlie the regulation of VEGF and its receptors in the uterine cervix are not

Published by Bioscientifica Ltd 


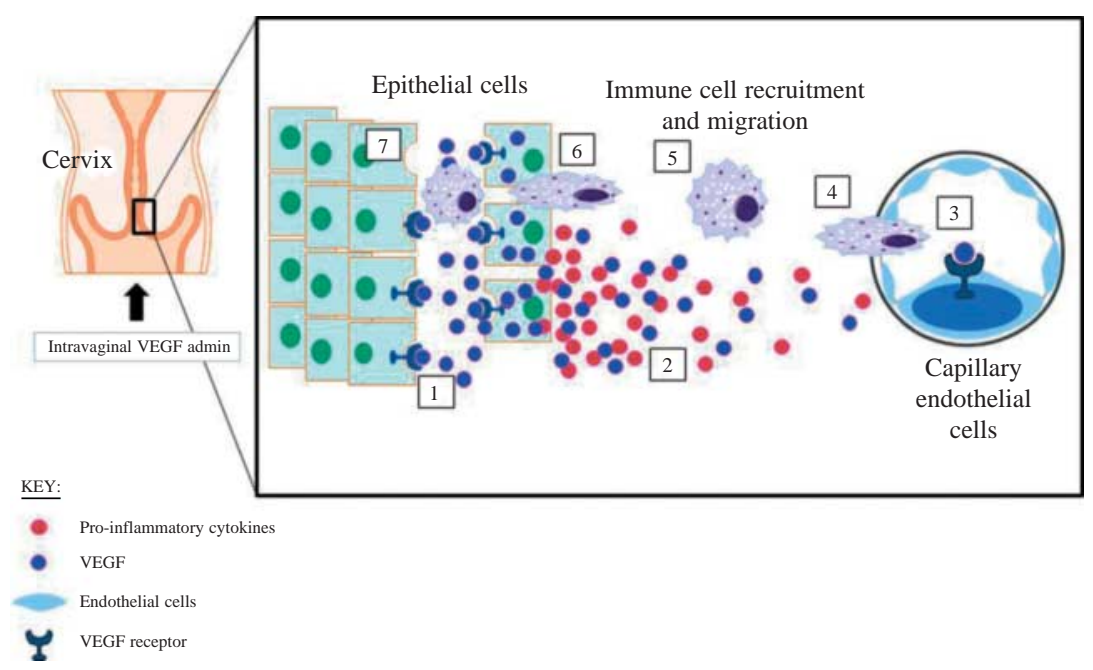

\section{Figure 8}

A proposed model for VEGF's effects on uterine cervical epithelial growth (7) and immune cell recruitment (2-6) into the uterine cervical lumen. These two events likely play a role in CR and local immune surveillance respectively.

completely known. We do know sensory-derived neuropeptides and inflammation-inducing factors can upregulate levels of VEGF in the uterine cervix, as well exogenous estrogen and hypoxia simulation (Mowa \& Papka 2004, Mowa et al. 2004, Nguyen et al. 2012, T Ohashi, S Jesmin, D Anumba and CN Mowa unpublished). Here, we show that mRNA expression of Vegf and that of its receptors increase over the course of pregnancy, with a sharp rise in late pregnancy. These findings are consistent with our earlier studies that characterized the profile of VEGF mRNA and protein expression and its receptors, and angiogenesis in the uterine cervix of pregnant rats over the course of pregnancy (Mowa et al. 2004). These two findings, together with other studies, show a temporal and/or causative relationship between VEGF and uterine cervical events, such as growth, angiogenesis (microvascular remodeling), hypoxia, plasma estrogen levels, inflammation, and neuropeptide expression. Here, we also show that exogenous VEGF administered to mice during early, but not late, pregnancy upregulates mRNA expression of endogenous VEGF and its receptors, which were attenuated by VEGF inhibitor. This suggests a possible existence of a positive VEGF autoregulatory mechanism during early pregnancy, which may magnify VEGF's biological effects and, importantly, possibly CR as well. The current observation is similar to findings of an earlier study that showed that low levels of VEGF significantly upregulated the expression of VEGF receptors (Flt1 and KDR), as well as enhanced adult neural
Exogenous VEGF (1) induces inflammatory response by epithelial cells, which may lead to establishment of a pro-inflammatory gradient (2) that attracts immune cells (3-6) to the site of stimulation or irritation.

progenitor cell differentiation into neurons in the rat. However, unlike our study, high doses downregulated expression of VEGF receptors as well as neurogenesis and they did not examine exogenous VEGF's effect on the levels of endogenous VEGF (Meng et al. 2006). Future studies will examine the influence of VEGF on the overall growth of the uterine cervix during pregnancy.

In conclusion, this study has shown that VEGF induces multiple alterations in the uterine cervical tissues of mice, notably increased epithelia growth, folding, edema, and increase in inter-epithelial paracellular spaces leading to recruitment of $\mathrm{WBC}$ into the uterine cervix. Collectively, these findings suggest that VEGF plays a role in local surveillance during CR by inducing an inflammatory response and uterine cervical growth (epithelial growth) during CR.

\section{Declaration of interest}

The authors declare that there is no conflict of interest that could be perceived as prejudicing the impartiality of the research reported.

\section{Funding}

This work was supported by Appalachian State University Office of Student Research and the Graduate School.

\section{Acknowledgements}

The authors thank Dr Guichuan Hou for his assistance in microscopy.

Published by Bioscientifica Ltd. 


\section{References}

Alican I \& Kubes P 1996 A critical role for nitric oxide in intestinal barrier function and dysfunction. American Journal of Physiology 270 G225-G237. 416.

Bani G \& Bigazzi M 1984 Morphological changes induced in mouse mammary gland by porcine and human relaxin. Acta Anatomica 119 149-154. (doi:10.1159/000145877)

Bani-Sacchi T, Bigazzi M, Bani D, Mannaioni PF \& Masini E 1995 Relaxin-induced increased coronary flow through stimulation of nitric oxide production. British Journal of Pharmacology 116 1589-1594. (doi:10.1111/j.1476-5381.1995.tb16377.x)

Barclay CG, Brennand JE, Kelly RW \& Calder AA 1993 Interleukin-8 production by the human cervix. American Journal of Obstetrics and Gynecology 169 625-632.

Berkes J, Viswanathan VK, Savkovic SD \& Hecht G 2003 Intestinal epithelial responses to enteric pathogens: effects on the tight junction barrier, ion transport and inflammation. Gut 52 439-451. (doi:10.1136/ gut.52.3.439)

Bird TA, Schooley K, Dower SK, Hagen H \& Virca GD 1997 Activation of nuclear transcription factor NF- kappaB by interleukin-1 is accompanied by casein kinase II-mediated phosphorylation of the p65 subunit. Journal of Biological Chemistry 272 32606-32612. (doi:10.1074/ jbc.272.51.32606)

Blaskewicz CD, Pudney J \& Anderson DJ 2011 Structure and function of intercellular junctions in human cervical and vaginal mucosal epithelia. Biology of Reproduction 85 97-104. (doi:10.1095/biolreprod. 110.090423)

van Bruggen N, Thibodeaux H, Palmer JT, Lee WP, Fu L, Cairns B, Tumas D, Gerlai R, Williams SP, van Lookeren Campagne M et al. 1999 VEGF antagonism reduces edema formation and tissue damage after ischemia/reperfusion injury in the mouse brain. Journal of Clinical Investigation 104 1613-1620. (doi:10.1172/JCI8218)

Buchanan DL, Kurita T, Taylor JA, Lubahn DB, Cunha GR \& Cooke PS 1998 Role of stromal and epithelial estrogen receptors in vaginal epithelial proliferation, stratification, and cornification. Endocrinology 139 4345-4352. (doi:10.1210/en.139.10.4345)

Caamano J \& Hunter CA 2002 NF-kappaB family of transcription factors: central regulators of innate and adaptive immune functions. Clinical Microbiology Reviews 15 414-429. (doi:10.1128/CMR.15.3.414-429. 2002)

Chen H, Ye D, Xie X, Chen B \& Lu W 2004 VEGF, VEGFRs expressions and activated STATs in ovarian epithelial carcinoma. Gynecologic Oncology 94 630-635. (doi:10.1016/j.ygyno.2004.05.056)

Cullen BM \& Harkness RD 1960 The effect of hormones on the physical properties and collagen content of the rat's uterine cervix. Journal of Physiology 152 419-436.

Dafni H, Landsman L, Schechter B, Kohen F \& Neeman M 2002 MRI and fluorescence microscopy of the acute vascular response to VEGF165: vasodilation, hyper-permeability and lymphatic uptake, followed by rapid inactivation of the growth factor. NMR in Biomedicine 2 120-131. (doi:10.1002/nbm.724)

De Groote M \& Fang F 1995 NO inhibitions: antimicrobial properties of nitric oxide. Clinical Infectious Diseases 21(Suppl 2) S162-S165. (doi:10.1093/clinids/21.Supplement_2.S162)

Downing SJ \& Sherwood OD 1985 The physiological role of relaxin in the pregnant rat. III. The influence of relaxin on cervical extensibility. Endocrinology 116 1215-1220. (doi:10.1210/endo-116-3-1215)

Dschietzig T \& Stangl K 2003 Relaxin: a pregnancy hormone as central player of body fluid and circulation homeostasis. Cellular and Molecular Life Sciences 60 688-700. (doi:10.1007/s00018-003-2169-x)

Fang F 1997 Mechanisms of nitric oxide-related antimicrobial activity. Journal of Clinical Investigation 99 2818-2825. (doi:10.1172/ JCI119473)
Ferrara N 2009 Vascular endothelial growth factor. Arteriosclerosis, Thrombosis, and Vascular Biology 29 789-791. (doi:10.1161/ATVBAHA. 108.179663)

Ferrara N \& Davis-Smyth T 1997 The biology of vascular endothelial growth factor. Endocrine Reviews 18 4-25. (doi:10.1210/er.18.1.4)

Hwang J-J \& Sherwood OD 1988 Monoclonal antibodies specific for rat relaxin. III. Passive immunization with monoclonal antibodies throughout the second half of pregnancy reduces cervical growth and extensibility in intact rats. Endocrinology 123 2486-2490. (doi:10.1210/ endo-123-5-2486)

Hwang J-J, Shanks RD \& Sherwood OD 1989 Monoclonal antibodies specific for rat relaxin. IV. Passive immunization with monoclonal antibodies during the antepartum period reduces cervical growth and extensibility, disrupts birth, and reduces pup survival in intact rats. Endocrinology 125 260-266. (doi:10.1210/endo-125-1-260)

Ito A, Hirota S, Mizuno H, Kawasaki Y, Takemura T, Nishiura T, Kanakura Y, Katayama Y, Nomura S \& Kitamura Y 1995 Expression of vascular permeability factor (VPF/VEGF) messenger RNA by plasma cells: possible involvement in the development of edema in chronic inflammation. Pathology International 45 715-720. (doi:10.1111/ j.1440-1827.1995.tb03387.x)

Kroc RL, Steinetz BG \& Beach VL 1959 The effects of estrogens, progestagens and relaxin in pregnant and non-pregnant laboratory rodents. Annals of the New York Academy of Sciences 75 942-980. (doi:10.1111/j.1749-6632.1959.tb44603.x)

Lee HY \& Sherwood OD 2005 The effects of blocking the actions of estrogen and progesterone on the rates of proliferation and apoptosis of cervical epithelial and stromal cells during the second half of pregnancy in rats. Biology of Reproduction 4 790-797. (doi:10.1095/biolreprod.105.043984)

Madara JL, Patapoff TW, Gillece-Castro B, Colgan SP, Parkos CA, Delp C \& Mrsny RJ 1993 5'-Adenosine monophosphate is the neutrophilderived paracrine factor that elicits chloride secretion from T84 intestinal epithelial cell monolayers. Journal of Clinical Investigation 91 2320-2325. (doi:10.1172/JCI116462)

Mahendroo MS, Porter A, Russell DW \& Word RA 1999 The parturition defect in steroid 5 alpha- reductase type 1 knockout mice is due to impaired cervical ripening. Molecular Endocrinology 13 981-992. (doi:10.1210/me.13.6.981)

McCormick BA, Parkos CA, Colgan SP, Carnes DK \& Madara JL 1998 Apical secretion of a pathogen-elicited epithelial chemoattractant activity in response to surface colonization of intestinal epithelia by Salmonella typhimurium. Journal of Immunology 160 455-466.

Meng H, Zhang Z, Zhang R, Liu X, Wang L, Robin AM \& Chopp M 2006 Biphasic effects of exogenous VEGF on VEGF expression of adult neural progenitors. Neuroscience Letters 393 97-101. (doi:10.1016/ j.neulet.2005.09.044)

Minjarez DA, Miller RT, Lindquist A, Anderson S \& Word RA 2000 Regulation of steroid hormone metabolism by $17-\beta$ hydroxysterioid dehydrogenate type 2 in the human cervix. Journal of the Society for Gynecologic Investigation 7 124A.

Monick MM, Carter AB, Gudmundsson G, Mallampalli R, Powers LS \& Hunninghake GW 1999 A phosphatidylcholine-specific phospholipase $\mathrm{C}$ regulates activation of $\mathrm{p} 42 / 44$ mitogen-activated protein kinases in lipopolysaccharide stimulated human alveolar macrophages. Journal of Immunology 162 3005-3012.

Mowa CN \& Papka RE 2004 The role of sensory neurons in cervical ripening: effects of estrogen and neuropeptides. Journal of Histochemistry and Cytochemistry 52 1249-1258.

Mowa CN, Jesmin S, Sakuma I, Togashi H, Yoshioka M, Hattori Y, Usip S \& Papka R 2004 Characterization of vascular endothelial growth factor (VEGF) in the uterine cervix over pregnancy: effects of denervation and implications for cervical ripening. Journal of Histochemistry and Cytochemistry 52 1665-1674. (doi:10.1369/jhc.4A6455.2004)

Mowa CN, Li T, Jesmin S, Folkesson HG, Usip SE, Papka RE \& Hou G 2008 Delineation of VEGF-regulated genes and functions in the cervix of 
pregnant rodents by DNA microarray analysis. Reproductive Biology and Endocrinology 6 64. (doi:10.1186/1477-7827-6-64)

Newell A, Thompson M \& Mowa CN 2008 VEGF mRNA levels are upregulated by lipopolyssacharide in the cervix of pregnant mice [abstract]. FASEB Journal 22 1003.10.

Nguyen BT, Minkiewicz V, McCabe E, Cecil J \& Mowa CN 2012 Vascular endothelial growth factor induces mRNA expression of pro-inflammatory factors in the uterine cervix of mice. Biomedical Research 33 363-372. (doi:10.2220/biomedres.33.363)

Pfundt R, van Ruissen F, van Vlijmen-Willems IM, Alkemade HA, Zeeuwen PL, Jap PH, Dijkman H, Fransen J, Croes H, van Erp PE et al. 1996 Constitutive and inducible expression of SKALP/elafin provides anti-elastase defense in human epithelia. Journal of Clinical Investigation 98 1389-1399. (doi:10.1172/JCI118926)

Roberts WG \& Palade GE 1995 Increased microvascular permeability and endothelial fenestration induced by vascular endothelial growth factor. Journal of Cell Science 108 2369-2379.

Rolfe V \& Milla P 1999 Nitric oxide stimulates cyclic guanosine monophosphate production and electrogenic secretion in Caco-2 colonocytes. Clinical Science 96 165-170. (doi:10.1042/CS19980243)

Savkovic S, Koutsouris A \& Hecht G 2002 Atypical PKC zeta regulates EPEC-induced inflammation through interaction with IkappaB kinase. Gastroenterology 122 A76.130.

Seibold JR, Korn JH, Simms R, Clements PJ, Moreland LW, Mayes MD, Furst DE, Rothfield N, Steen V, Weisman M et al. 2002 Recombinant human relaxin in the treatment of scleroderma. A randomized, double blind, placebo-controlled trial. Annals of Internal Medicine $132871-879$
Senger DR, Perruzzi CA, Feder J \& Dvorak HF 1986 A highly conserved vascular permeability factor secreted by a variety of human and rodent tumor cell lines. Cancer Research 46 5629-5632.

St-Louis J \& Massicotte G 1985 Chronic decrease of blood pressure by rat relaxin in spontaneously hypertensive rats. Life Sciences 37 1351-1357. (doi:10.1016/0024-3205(85)90251-6)

Tischer E, Mitchell R, Hartman T, Silva M, Gospodarowicz D, Fiddes JC \& Abraham JA 1991 The human gene for vascular endothelial growth factor. Multiple protein forms are encoded through alternative exon splicing. Journal of Biological Chemistry 266 11947-11954.

Unemori EN, Erikson ME, Rocco SE, Sutherland KM, Parsell DA, Mak J \& Grove BH 1999 Relaxin stimulates expression of vascular endothelial growth factor in normal human endometrial cells in vitro and is associated with menometrorrhagia in women. Human Reproduction 14 800-806. (doi:10.1093/humrep/14.3.800)

Word RA, Lo X-H, Hnat M \& Carrick K 2007 Dynamics of cervical remodeling during pregnancy and parturition: mechanisms and current concepts. Seminars in Reproductive Medicine 25 69-80. (doi:10.1055/s-2006-956777)

Yao L, Cooke PS, Meling DD, Shanks RD, Jameson JL \& Sherwood OD 2010 The effect of relaxin on cell proliferation in mouse cervix requires estrogen receptor $\alpha$ binding to estrogen response elements in stromal cells. Endocrinology 151 2811-2818. (doi:10.1210/en.2009-1327)

Zarrow MX \& Yochim J 1961 Dilation of the uterine cervix of the rat and accompanying changes during the estrous cycle, pregnancy and following treatment with estradiol, progesterone, and relaxin. Endocrinology 69 292-304. (doi:10.1210/endo-69-2-292)

Received in final form 31 January 2013

Accepted 4 February 2013

Accepted Preprint published online 4 February 2013 (c) 2013 Society for Endocrinology Printed in Great Britain 